\title{
Association between smoking and tuberculosis infection: a population survey in a high tuberculosis incidence area
}

\author{
S den Boon, S W P van Lill, M W Borgdorff, S Verver, E D Bateman, C J Lombard, D A Enarson, \\ $\mathrm{N}$ Beyers
}

See end of article for authors' affiliations

Correspondence to: Ms S den Boon, Centre for TB Research and Education, Department of Paediatrics and Child Health, Stellenbosch University, P O Box 19063, 7505 Tygerberg, Cape Town, South Africa 14321823@sun.ac.za

Received 5 July 2004 Accepted 6 April 2005
Thorax 2005:60:555-557. doi: 10.1136/thx.2004.030924

Background: Associations between smoking and tuberculosis disease including death from tuberculosis have been reported, but there are few reports on the influence of smoking on the risk of developing Mycobacterium tuberculosis infection. The aim of this study was to determine the association between smoking and $M$ tuberculosis infection.

Methods: In a cross sectional population survey, data on smoking and tuberculin skin test (TST) results of 2401 adults aged $\geqslant 15$ years were compared.

Results: A total of 1832 (76\%) subjects had a positive TST ( $\geqslant 10 \mathrm{~mm}$ induration). Of 1309 current smokers or ex-smokers, $1070(82 \%)$ had a positive TST. This was significantly higher than for never smokers (unadjusted OR 1.99, 95\% confidence interval (CI) 1.62 to 2.45). A positive relationship with pack-years was observed, with those smoking more than 15 pack-years having the highest risk (adjusted OR 1.90, $95 \% \mathrm{Cl} 1.28$ to 2.81 ).

Conclusion: Smoking may increase the risk of $M$ tuberculosis infection.
1 n a recent large epidemiological study, $50 \%$ of deaths from tuberculosis among Indian men was attributed to smoking. ${ }^{1}$ While an association between smoking and tuberculosis disease has been shown in various studies, ${ }^{2-7}$ it is less clear to what extent smoking increases the risk of Mycobacterium tuberculosis infection, the risk of progression from infection to disease, or the risk of death among tuberculosis patients.

We report here a population survey conducted in two urban communities in Cape Town, South Africa that provides evidence that smoking may increase the risk of tuberculosis infection. The study area in which we have performed epidemiological research for more than 10 years has a population of 36334 and $97.9 \%$ are of mixed ethnicity (categorised as "coloured"; Statistics South Africa: Census 2001). The tuberculosis notification rate in the area is 238 new smear-positive cases per 100000 population per year (1993$8),{ }^{8}$ and the prevalence of HIV infection is estimated to be lower than the overall rate for the Western Cape province at the time of the survey $(12.4 \%(8.8-15.9 \%)$ in 2002$) .{ }^{9}$

\section{METHODS}

A random sample of $15 \%$ of the residential addresses was selected. Of the 833 selected addresses, the head of the household of $218(26 \%)$ declined to participate. These addresses were replaced by neighbouring addresses according to fixed rules. Written informed consent was obtained from every adult ( $\geqslant 15$ years) and the study was approved by the research ethics committees of Stellenbosch University and the University of Cape Town.

Data collection methods included a tuberculin skin test (TST) and a precoded questionnaire with questions on smoking. For the TST we used an intradermal injection of $2 \mathrm{TU}(0.1 \mathrm{ml})$ PPD RT 23 into the ventral aspect of the left forearm. The induration was measured $48-72$ hours later.

Smoking was defined as having ever smoked for at least 1 year. The average number of cigarettes smoked per day was recorded for all ex-smokers and current smokers. The number of pack-years smoked was calculated as the average number of cigarettes smoked per day multiplied by the duration of smoking divided by 20. Infection with $M$ tuberculosis was defined as a TST of $10 \mathrm{~mm}$ or more, referred to as a positive TST. The $10 \mathrm{~mm}$ cut off point is conventionally used and appeared justified in this population since intermediate reactions to TST, usually attributed to environmental mycobacteria, were uncommon (fig 1).

The following potential confounders were considered: age, sex, education level, body mass index (BMI), and individual monthly income. The possible interactions between packyears and the variables age and sex were investigated. Odds ratios (OR) and their 95\% confidence intervals (95\% CI) were determined to identify risk factors, and random effects logistic regression was used to control for confounding as well as for possible clustering at the address level.

\section{RESULTS}

Of 3512 adults who completed the questionnaire, a TST result was recorded in 2443 (70\%). Data on smoking habits were incomplete in 42 individuals so analyses were performed on 2401. Compared with subjects excluded from the analyses, those included were less often male (unadjusted OR 0.57, $95 \%$ CI 0.49 to 0.65 ), were less often current or ex-smokers (unadjusted OR $0.82,95 \%$ CI 0.70 to 0.94 ), and fewer had an income above 2000 Rand (300 US\$) (unadjusted OR 0.62, 95\% CI 0.51 to 0.76 ).

Of the 2401 adults analysed, $1832(76 \%)$ had a positive TST and $1309(55 \%)$ were current or ex-smokers; $82 \%(\mathrm{n}=1070)$ of the 1309 current or ex-smokers had a positive TST compared with $70 \%(\mathrm{n}=762)$ of the 1092 never smokers (unadjusted OR $1.99,95 \%$ CI 1.62 to 2.45 ). Men were more likely to have a positive TST than women (unadjusted OR 1.34, $95 \%$ CI 1.08 to 1.65 ; table 1 ). A positive TST was more common in the 25-44 year age group than in other age groups. The proportion of individuals with a positive TST increased with income, but not with education level or BMI (data not shown).

In the multiple logistic regression analyses, income and sex did not confound the association between smoking and infection. However, as sex was associated with smoking and with having a positive TST, it was retained in the model. The 


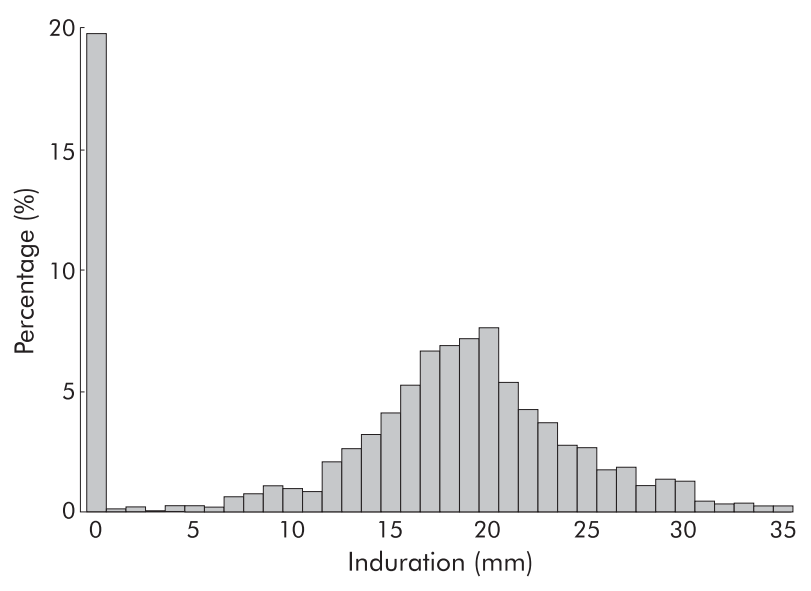

Figure 1 Distribution of induration of tuberculin skin test in 2401 adults.

association between infection and pack-years smoked was not significantly different for the different age and sex strata. After adjusting for age and sex, there was a significant association between smoking and a positive TST (adjusted OR $1.77,95 \%$ CI 1.41 to 2.21 ). The probability of a positive TST seemed to increase slightly with the number of pack-years smoked, although the differences between the different packyear categories were not significant (table 1).

\section{DISCUSSION}

This study shows that current or ex-smokers had a higher prevalence of $M$ tuberculosis infection than never smokers and that there was a slightly higher risk of infection for those who smoked more than 15 pack-years than for those who smoked less, although this was not significant. This suggests that the increased risk of disease and death from tuberculosis among smokers may be due, at least in part, to an increased risk of smokers becoming infected with $M$ tuberculosis.
An unexpected finding was the positive association between a positive TST and income. It should be noted, however, that the mean incomes in the study area are low, and that the categorisation threshold used in the analyses identifies only the poorest in the community. Nevertheless, the reason for their lower TST rates requires further study, including the possibility of lower risk of exposure through fewer social contacts.

Our study confirms previous studies that showed an association between smoking and tuberculosis infection in at risk groups. ${ }^{30-14}$ For example, in an immigrant population Plant et $a l^{10}$ reported a higher risk of infection among smokers which increased with duration of smoking. In contrast to previous studies investigating specific high risk groups, ${ }^{10-14}$ the current study is the first to investigate the association between smoking and tuberculosis infection in a cross sectional population survey in a high incidence community.

The reason for the increased risk of infection in smokers is unclear, but may be explained by the effects of smoking on pulmonary host defences. Smoking has been shown to reduce natural killer cytotoxic activity, to suppress $\mathrm{T}$ cell function in both lung and blood, to impair mucociliary clearance of particles, and to increase numbers of alveolar macrophages in the lower respiratory tract. Cells of the macrophage-phagocytic group influence immediate or innate immunity through their handling and elimination of mycobacteria, and products of cigarette smoke may therefore favour persistence and/or replication of ingested mycobacteria by impairing the macrophage or dendritic cell function. ${ }^{15} 16$

To take possible sources of bias into account we have considered the following. Men and persons in the highest income category are under-represented, but this is unlikely to be of significance as neither sex nor income was a confounder for the association between smoking and positive TST. Smokers and ex-smokers were also slightly underrepresented but still comprised 55\% of the sample, and we can see no reason to assume that the smokers who had undergone a TST might be different from those who had not. A weakness of the study is that we did not test the HIV status

Table 1 Risk factors for $M$ tuberculosis infection

\begin{tabular}{|c|c|c|c|c|c|}
\hline & \multirow[b]{2}{*}{$\mathrm{TST} \geqslant 10 \mathrm{~mm}$} & \multirow[b]{2}{*}{ Total } & \multirow[b]{2}{*}{$\%$ TST $\geqslant 10 \mathrm{~mm}$} & \multicolumn{2}{|l|}{ Odds ratio } \\
\hline & & & & Unadjusted $(95 \% \mathrm{Cl})$ & $\begin{array}{l}\text { Adjusted } \\
\mathbf{n}=2328\end{array}$ \\
\hline \multicolumn{6}{|c|}{ Smoking (pack-years) } \\
\hline Never smoked & 769 & 1102 & 70 & 1 & 1 \\
\hline$<5$ & 443 & 550 & 81 & 1.86 (1.42 to 2.43$)$ & 1.77 (1.33 to 2.35$)$ \\
\hline $5-15$ & 343 & 407 & 84 & 2.39 (1.74 to 3.29$)$ & 1.77 (1.25 to 2.50$)$ \\
\hline$\geqslant 15$ & 236 & 288 & 82 & 2.00 (1.40 to 2.84$)$ & 1.90 (1.28 to 2.81$)$ \\
\hline Unknown & 41 & 54 & 76 & & \\
\hline \multicolumn{6}{|l|}{ Sex } \\
\hline Female & 1100 & 1477 & 74 & 1 & 1 \\
\hline Male & 731 & 923 & 79 & 1.34 (1.08 to 1.65$)$ & 1.24 (0.99 to 1.56$)$ \\
\hline Unknown & 1 & 1 & 100 & & \\
\hline \multicolumn{6}{|l|}{ Age (years) } \\
\hline $15-24$ & 432 & 651 & 66 & 1 & 1 \\
\hline $25-34$ & 444 & 498 & 89 & 4.47 (3.14 to 6.37$)$ & 4.30 (3.00 to 6.17$)$ \\
\hline $35-44$ & 412 & 484 & 85 & $3.16(2.28$ to 4.37$)$ & 2.82 (2.00 to 3.99 ) \\
\hline $45-54$ & 263 & 330 & 80 & $2.11(1.50$ to 2.97$)$ & 1.96 (1.35 to 2.85$)$ \\
\hline$\geqslant 55$ & 264 & 408 & 65 & $0.88(0.66$ to 1.18$)$ & 0.88 (0.64 to 1.22$)$ \\
\hline Unknown & 17 & 30 & 57 & & \\
\hline \multicolumn{6}{|l|}{ Income (Rands)† } \\
\hline$<500$ & 804 & 1088 & 74 & 1 & \\
\hline 500-1999 & 685 & 893 & 77 & $1.18(0.94$ to 1.48$)$ & \\
\hline$\geqslant 2000$ & 315 & 381 & 83 & 1.93 (1.38 to 2.68$)$ & \\
\hline Unknown & 28 & 39 & 72 & & \\
\hline Total & 1832 & 2401 & & & \\
\hline
\end{tabular}


of participants and were therefore not able to correct for HIV status. Confounding factors that were taken into consideration were individual monthly income, BMI, and education level. However, we cannot entirely discount the possibility that socioeconomic and behavioural differences other than smoking may have affected the relationship between smoking and tuberculous infection.

We conclude that smoking may increase the risk of $M$ tuberculosis infection. We propose that further studies be conducted to investigate this association and to establish whether smoking reduction strategies contribute to tuberculosis control.

\section{ACKNOWLEDGEMENTS}

The authors thank Dr Ivan Toms, Director of Health, City of Cape Town for permission to work in the community, Neil White and Elvis Irusen for their contribution to the design of the study, Kathy Lawrence for the data management, the sisters and the fieldworkers for their help in gathering data, and the people of Ravensmead and Uitsig for their participation.

\section{Authors' affiliations}

S den Boon, S W P van Lill, N Beyers, Centre for TB Research and Education, Department of Paediatrics and Child Health, Stellenbosch University, P O Box 19063, 7505 Tygerberg, Cape Town, South Africa S den Boon, M W Borgdorff, Academic Medical Centre, Amsterdam, The Netherlands

M W Borgdorff, S Verver, KNCV Tuberculosis Foundation, The Hague, The Netherlands

E D Bateman, Division of Pulmonology, Department of Medicine, University of Cape Town, Cape Town, South Africa

C J Lombard, Biostatistics Unit, Medical Research Council, Cape Town, South Africa

D A Enarson, International Union Against Tuberculosis and Lung Diseases, Paris, France

This study was funded by Stellenbosch University through funding from the South African Department of Trade and Industry (THRIP fund) and the Glaxo Smith Kline Action TB Programme, and the University of Cape Town Lung Institute. MWB and SV were supported by Areas Global TB Vaccine Foundation. None of the funding sources had any role in the study design; the collection, analyses, and interpretation of data; in the writing of the report; or in the decision to submit the paper for publication.

$N B, E B, S v L, D E$, and $M B$ were involved in the study design and writing of the manuscript. $\mathrm{SdB}$ performed the statistical analysis and wrote the paper. Advice on statistics was given by $\mathrm{CL}, \mathrm{SV}$ and MB. All authors participated in interpretation of the results. NB supervised the data collection and $M B$ the statistical analyses.

\section{REFERENCES}

1 Gajalakshmi V, Peto R, Kanaka TS, et al. Smoking and mortality from tuberculosis and other diseases in India: retrospective study of 43000 adult male deaths and 35000 controls. Lancet 2003;362:507-15.

2 leung CC, Yew WW, Chan CK, et al. Smoking and tuberculosis in Hong Kong. Int J Tuberc Lung Dis 2003;7:980-6.

3 Maurya V, Vijayan VK, Shah A. Smoking and tuberculosis: an association overlooked. Int J Tuberc Lung Dis 2002;6:942-51.

4 Kolappan C, Gopi PG. Tobacco smoking and pulmonary tuberculosis. Thorax 2002:57:964-6.

5 Alcaide J, Altet MN, Plans $P$, et al. Cigarette smoking as a risk factor for tuberculosis in young adults: a case-control study. Tuberc Lung Dis 1996;77:112-6.

6 Lowe CR. An association between smoking and respiratory tuberculosis. BMJ 1956:1081-6.

7 Yu G. Risk factors associated with the prevalence of pulmonary tuberculosis among sanitary workers in Shanghai. Tubercle 1988;69:105-12.

8 Verver S, Warren RM, Munch Z, et al. Transmission of tuberculosis in a high incidence urban community in South Africa. Int J Epidemiol 2004:33:351-7.

9 Department of Health. Summary report: National HIV and syphilis antenatal sero-prevalence survey in South Africa 2002, Available at http:// 196.36.153.56/doh/aids/index.html

10 Plant AJ, Watkins RE, Gushulak B, et al. Predictors of tuberculin reactivity among prospective Vietnamese immigrants: the effect of smoking. Epidemiol Infect 2002;128:37-45.

11 McCurdy SA, Arretz DS, Bates RO. Tuberculin reactivity among California Hispanic migrant farm workers. Am J Ind Med 1997;32:600-5.

12 Nisar M, Williams CSD, Ashby D, et al. Tuberculin testing in residential homes for the elderly. Thorax 1993;48: 1257-60.

13 Anderson RH, Thompson S, Francisco S, et al. Cigarette smoking and tuberculin skin test conversion among incarcerated adults. Am J Prev Med 1997; 13:175-81.

14 Kuemmerer JM, Comstock GW. Sociologic concomitants of tuberculin sensitivity. Am Rev Respir Dis 1967;96:885-92.

15 Phillips DE, Hill L, Weller $P$, et al. Tobacco smoke and the upper airway. Clin Otolaryngol 2003;28:492-6.

16 Sopori M. Effects of cigarette smoke on the immune system. Nat Rev Immunol 2002;2:372-7. 